\title{
ENTRE LA TRANSPARENCIA Y LA OPACIDAD. ANÁLISIS DEL PAPEL DE LAS REGLAS EN EL RAZONAMIENTO JUDICIAL
}

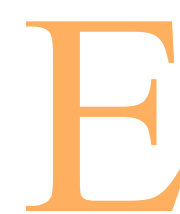

n el entorno académico acostumbra tener vigencia una regla de estilo que desaconseja emplear en los títulos de los trabajos expresiones que puedan provocar perplejidad de sus potenciales lectores. En el título de este artículo hay, sin embargo, al menos dos expresiones -«transparencia» y «opacidad»- cuyo sentido puede no resultar, de entrada, demasiado claro. El sentido en que se habla de «transparencia» y «opacidad» de las reglas en cierta literatura se verá clarificado enseguida, por lo que aquí no introduciré más que una ilustración inicial, valiéndome de la regla de no usar expresiones desconcertantes en los títulos de los trabajos. Si cada vez que titulara uno de ellos reflexionara para decidir si seguir o no esta regla, consideraría a la misma como completamente transparente. Por el contrarío, si siguiera la regla a pies juntillas y nunca me planteara dejarla de lado, la consideraría como absolutamente opaca.

Dejando por el momento a un lado las cuestiones terminológicas del trabajo, conviene precisar antes de nada cuál es objeto del mismo: consiste en realizar una aproximación a la forma en la que las reglas de mandato se integran en el razonamiento práctico de los órganos judiciales. Se trata de analizar el papel o función ${ }^{1}$ que dichas reglas cumplen o pretenden cumplir en el razonamiento justificativo de decisiones que llevan a cabo los órganos jurisdiccionales. A este respecto quizá no esté de más advertir de antemano que el punto de vista que adopto no es puramente descriptivo, sino que trato de reconstruir racionalmente las razones que dichos órganos alegan -en cuanto que tales órganos jurisdiccionales- cuando tienen que justificar sus decisiones.

\footnotetext{
${ }^{1}$ Voy a emplear la expresión «perspectiva funcional» para referirme a una de las perspectivas de análisis de las normas expuestas por Manuel Atienza y Juan Ruiz Manero en Las piezas del Derecho. En concreto se trataría de aquella perspectiva que da cuenta de las normas en términos de «razones para la acción» [cfr. ob. cit, Ariel Derecho, Barcelona, 1996, págs. 6 a 7 y 19].
} 
Me voy a ocupar de cuatro modelos sobre las reglas de mandato: la concepción de las reglas indicativas de Donald Regan; la concepción del Derecho como sistema excluyente de Joseph Raz; la concepción de las reglas y los principios de Manuel Atienza y Juan Ruiz Manero; y el positivismo presuntivo de Frederick Schauer. No expongo estos modelos como unidades aisladas, carentes de relación entre sí, sino que me sirvo de un hilo conductor para guiar la exposición: Pretendo mostrar que, pese a las notables diferencias en la terminología empleada, todas estas concepciones conciben el papel de las reglas de mandato en el razonamiento práctico de forma semejante. En concreto, utilizando la terminología de Regan -con la que pronto nos familiarizaremos- veremos que, para todos estos autores, las reglas desarrollan su función entre la «completa transparencia» y la «absoluta opacidad».

Más que un orden cronológico, en la exposición de las concepciones he pretendido seguir un orden sistemático. Así, el primer modelo del que me ocupo es el de Regan, pese a que sus dos trabajos sobre las reglas indicativas son posteriores a los de Raz y en buena medida -como el propio Regan reconoce- están estimulados por las tesis de éste ${ }^{2}$. A mi juicio, este orden permite partir de una concepción más sencilla, centrada en el punto de vista de las razones para la acción de un agente racional y autónomo, para avanzar posteriormente a concepciones más acabadas -como la de Raz, la de Atienza y Ruiz Manero y la de Schauer- en las que se tienen en cuenta factores de complejidad característicos de los sistemas jurídicos.

\section{La concepción de las reglas indicativas de Donald H. Regan}

Con su concepción de las reglas indicativas, Regan pretende dar cuenta del papel que juegan las normas de mandato en el razonamiento práctico del aceptante del Derecho. Se trata -empleando sus propias palabras- «de explicar aquello en lo que consiste el halo [normativo] del Derecho», recurriendo para ello a la noción de regla indicativa ${ }^{3}$.

Regan define las reglas indicativas como «aquellas guías para la acción que se adoptan para afrontar los casos en los que tenemos una información incompleta, para moderar nuestra tendencia a la parcialidad, para economizar los costes empleados en la toma de decisiones, etc.». La idea de Regan, que -como vamos a ver- coincide ampliamente con la de $\mathrm{Raz}^{4}$, es la de que

\footnotetext{
${ }^{2}$ Cfr. «Law's Halo», Philosophy and Law, J. Coleman y E. Frankel Paul eds., Basil Blackwell, Oxford, 1987, págs. 15 a 30 y «Authority and Value: Reflections on Raz's Morality of Freedom», Southern California Law Review, núm. 62, 1989, págs. 995 a 1.095.

${ }^{3}$ De todo ello me he ocupado con detalle en Sobre la justificación de la autoridad, Centro de Estudios Constitucionales, Madrid, 1996, págs. 170 a 201.

${ }^{4}$ Raz no habla tanto de reglas indicativas como de reglas de la experiencia. Por lo demás, la noción de regla de la experiencia es también empleada por Raz para realizar una primera aproximación a las normas de mandato.
} 
estas reglas operarían como una suerte de mecanismo de minimización de errores en condiciones de incertidumbre o cuando no es posible emplear el tiempo y esfuerzo necesario para desarrollar una deliberación completa. La regla que establece el límite máximo de velocidad en autopista en 120 kilómetros a la hora puede ser vista como un ejemplo de regla indicativa. Así entendida, esta regla evitaría al sujeto normativo tener que calcular, de acuerdo con las circunstancias de cada caso, cuál es la velocidad máxima a la que puede razonablemente circular.

Las características que Regan atribuye a las reglas indicativas, podrían sintetizarse de la siguiente forma: En primer lugar, las reglas indicativas, aunque «indican»-como su propio nombre sugiere- la posible presencia de una «razón intrínseca», no constituyen por sí mismas razones intrínsecas. En segundo lugar, las reglas indicativas tienen un carácter provisional, pues pueden ser abandonadas cuando otra regla alternativa refleja mejor la totalidad de consideraciones que se supone que la regla indica. Y, finalmente -aunque pueda parecer paradójico- las reglas indicativas son vinculantes en un sentido significativo: Un agente racional puede estar compelido a actuar sobre la base de reglas indicativas si están basadas en valores que el agente está obligado a respetar (con independencia de sus propios deseos y preferencias) y constituyen la mejor guía disponible para la acción ${ }^{5}$.

Regan resume su caracterización de las reglas indicativas señalando que éstas no son ni completamente transparentes ni absolutamente opacas. Un individuo trata una regla como completamente transparente cuando considera que sólo es racional hacer lo que la regla establece cuando se tiene la plena certeza de que ésta conduce a la decisión correcta. Pero, como ya sabemos, estar dispuesto a abandonar o ignorar las reglas indicativas si surgen circunstancias que parecen aconsejarlo no es lo mismo que tratar las reglas indicativas como perfectamente transparentes en todos los $\operatorname{casos}^{6}$.

Que las reglas indicativas no sean completamente transparentes no significa que éstas sean absolutamente opacas. Un agente considera una regla como absolutamente opaca cuando entiende que ha de hacer siempre lo que la regla establece, sin atender a las razones que la justifican. Aunque Regan considera que las reglas indicativas pueden ser opacas en un grado significativo, estima también que nunca pueden serlo perfectamente, ya que en principio son siempre susceptibles de revisión?

${ }^{5}$ D. H. Regan, «Authority and Value: Reflections on Raz's Morality of Freedom», ob cit., págs. 1005 a 1010.

${ }^{6}$ D. H. Regan, «Authority and Value: Reflections on Raz’s Morality of Freedom», ob cit., pág. 1011.

${ }^{7}$ D. H. Regan, «Authority and Value: Reflections on Raz’s Morality of Freedom», ob cit., pág. 1012. 


\section{El Derecho como sistema excluyente: la concepción de Joseph Raz}

\section{a) Las normas de mandato como razones excluyentes}

Por su parte, la caracterización que Raz realiza de las normas de mandato es bastante semejante a la de las reglas indicativas de Regan. Según Raz, seguir una norma de mandato significa que actuamos sobre la base de la creencia de que la norma es una razón válida para que, cuando se den las condiciones de aplicación, hagamos el acto normativo y de que simultáneamente es también una razón válida para no actuar sobre la base de las razones aplicables al caso ${ }^{8}$. Volviendo al ejemplo de la regla que limita la velocidad en autopista, la norma no se toma sólo como una razón para no exceder los 120 kilómetros por hora -esto es, como una razón de primer orden-, sino también como una razón de segundo orden que resuelve conflictos prácticos excluyendo razones sobre cuál es la velocidad máxima a la que se puede razonablemente circular. Raz denomina razón protegida a esta combinación sistemática de una razón de primer orden para realizar el acto exigido y una razón excluyente para no actuar por ciertas consideraciones ${ }^{9}$.

Ahora bien, Raz advierte también que la presencia de una norma de mandato no resuelve automáticamente los problemas prácticos. Puede haber otras razones en conflicto no excluidas por la norma. De forma específica Raz se refiere a las consideraciones relativas al alcance de las reglas y a las excepciones a las mismas ${ }^{10}$, de las que me ocuparé más adelante. Pero estos factores de complicación se presentarían sólo en una minoría de supuestos. Para nuestro autor, en una mayoría de casos la presencia de una norma resulta decisiva. La finalidad de tener normas residiría precisamente en lograr la simplificación. Por lo general, dado que la norma opera como una razón excluyente, no ha de competir con la mayoría de las demás razones que es probable que sean aplicables a situaciones gobernadas por la norma, pues ésta las excluye. De este modo, Raz sostiene que las normas tienen una relativa independencia respecto de las razones que las justifican. En la mayoría de casos no necesitamos saber cuáles son las razones que justifican una norma para poder aplicarla correctamente.

Para concluir con el análisis de las normas de mandato como razones excluyentes cabe que establezcamos una comparación con la concepción de Regan que ya hemos examinado. Si recordamos la tesis de Regan en tomo a las

\footnotetext{
${ }^{8}$ Cfr. Razón practica y normas (trad. de Juan Ruiz Manero), Madrid, Centro de Estudios Constitucionales, 1991, pág. 82.

${ }^{9}$ Cfr. J. Raz, La autoridad del Derecho. Ensayos sobre derecho y moral (trad. de R. Tamayo Salmorán), UNAM, México, 1982, pág. 33.

${ }^{10}$ Cfr. Razón práctica y normas, ob. cit., págs. 89, 91 y 232.
} 
reglas indicativas, podemos establecer una clara analogía con la concepción de Raz. De un lado -nos decía Regan- las reglas indicativas no son completamente transparentes, lo que concuerda perfectamente con la idea de Raz de que las razones excluyentes impiden actuar en todos los supuestos sobre la base del cálculo de razones de primer orden aplicables al caso. Es decir, guiarse por una norma de mandato es incompatible con volver a abrir ante cada caso la deliberación a todas las razones de primer orden concurrentes. Las ventajas de guiarse por normas de mandato se diluirían, al igual que sucede con las reglas indicativas, si se consideran como transparentes a las razones que las sustentan. De otro lado, Regan señalaba que las reglas indicativas tampoco son completamente opacas, lo que supone que no siempre el sujeto ha de hacer lo que la regla establece. Así, como acabamos de ver, Raz mantiene que las normas de mandato no siempre resuelven automáticamente los problemas prácticos y que, en una minoría de supuestos, se hace imprescindible recurrir a las razones que justifican las normas. Sobre esta cuestión volveré más adelante.

Hasta aquí hemos visto la manera en la que un agente racional y aislado que aceptara el Derecho integraría las normas de mandato en su razonamiento práctico; pero nada hemos dicho de la forma en la que estas normas se integran en las deliberaciones prácticas de los órganos jurisdiccionales. Ello exige que reparemos en la tesis de Raz sobre la naturaleza del Derecho como sistema normativo institucional izado ${ }^{11}$.

\section{b) La naturaleza del Derecho como «sistema normativo institucionalizado»}

Raz señala que es un rasgo del Derecho, en tanto que sistema normativo institucionalizado, contar con órganos primarios (principalmente los tribunales y los jueces) que deben evaluar las disputas sobre la base de las reglas del sistema bajo el que operan, excluyendo todas aquellas razones que tengan carácter extrajurídico. Han de seguir un cierto cuerpo de normas con independencia de sus opiniones sobre su contenido, lo que no es incompatible con que les esté permitido actuar sobre la base de sus propias opiniones cuando el propio Derecho les habilita para ello. Pero, mientras que no se produzca tal habilitación, los tribunales están vinculados a considerar la actuación de los individuos de acuerdo con los estándares jurídicos, con exclusión de todas las demás razones. En suma, los órganos primarios deben considerar al sistema jurídico como un sistema excluyente. Sus normas excluyen la aplicación de razones, estándares y normas que no pertenezcan al sistema o no sean reconocidas por él. El punto de vista jurídico es un punto de vista excluyente.

\footnotetext{
${ }^{11}$ Dicha concepción está desarrollada básicamente en Razón practica y normas, ob. cit., págs. 154 a 167 y La autoridad del Derecho, ob cit., págs. 140 a 146.
} 
Antes de concluir con el examen de la concepción del Derecho de Raz conviene que reparemos en cierta ambigüedad de su tesis sobre los sistemas jurídicos como sistemas excluyentes. Esta tesis aparece reflejada en su obra al menos con dos sentidos diferentes, aunque profundamente relacionados entre sí. En ocasiones el carácter excluyente del Derecho parece aludir a que éste impone a los jueces y tribunales la obligación de juzgar los casos desde las razones suministradas por el propio Derecho, excluyendo aquellas pautas que tengan un carácter extrajurídico. En cambio, otras veces, este carácter excluyente del Derecho se predica en relación a un tipo concreto de enunciado normativo: las normas de mandato.

El análisis de las normas de Atienza y Ruiz Manero al que voy a referirme a continuación se centra básicamente en el segundo sentido de los sistemas jurídicos como sistemas excluyentes. Como vamos a ver, dicho análisis parte de la usual distinción, dentro las normas de mandato, entre reglas y principios. Ahora bien, es precisamente la noción de razón excluyente la que sirve para caracterizar a las reglas por oposición a los principios. No resulta, por lo tanto, en absoluto pacífica la tesis de Raz de que todas las normas de mandato pretenden configurar razones excluyentes para sus destinatarios.

\section{Las reglas como razones excluyentes: la concepción de Atienza y Ruiz Manero}

Para explicar la diferencia que para Manuel Atienza y Juan Ruiz Manero existiría, desde un punto de vista funcional, entre reglas y principios, debo antes aludir brevemente al análisis estructural que estos autores realizan de ambos tipos de enunciados jurídicos. A juicio de estos autores, mientras que los principios configuran los casos de forma abierta, las reglas lo hacen de forma cerrada. En las reglas, las propiedades que conforman el caso constituyen un conjunto finito y cerrado, en cambio, en los principios, no puede formularse una lista cerrada de las mismas, puesto que tales condiciones no están siquiera genéricamente determinadas ${ }^{12}$.

Son precisamente estas diferencias estructurales entre reglas y principios las que llevan a trazar en el plano funcional -en el sentido de «análisis en términos de razones para la acción»- también una clara distinción entre ambos tipos de enunciados. El análisis de estos autores considera básicamente los principios y las reglas en cuanto pautas dirigidas a lo que Raz llama órganos primarios. Adoptando la conocida terminología del último Hart, estos autores consideran las reglas jurídicas como razones perentorias para

\footnotetext{
${ }^{12}$ Cfr. Manuel Atienza y Juan Ruiz Manero, Las piezas del Derecho, ob. cit., págs. 8 a 9.
} 
la acción ${ }^{13}$. La noción de razón perentoria viene a coincidir con la de razón protegida de Raz, a la que acabo de referirme. Esto es, la combinación de una razón de primer orden para realizar la acción exigida -en el contexto que nos ocupa, para dictar una resolución cuyo contenido corresponda con el de la regla-, y de una razón excluyente para prescindir del resultado al que llevaría una deliberación independiente por parte de su destinatario sobre los argumentos en pro y en contra de realizar la acción. Lo que, en este mismo contexto, significa una razón para excluir que el contenido de la resolución se fundamente en la apreciación por parte del órgano jurisdiccional de cuál fuera, atendiendo a los méritos del caso, la mejor resolución a dictar. En suma, para estos autores las reglas estarían destinadas a que, cuando se dan sus condiciones de aplicación, los órganos primarios excluyan, en cuanto base de su resolución, su propio juicio acerca del balance de razones aplicables y adopten como tal base el contenido de la regla ${ }^{14}$.

Por su parte, los principios no constituirían para Atienza y Ruiz Manero razones perentorias o protegidas, ya que no están destinados a excluir la deliberación por parte del órgano jurisdiccional acerca del contenido de la resolución a dictar, sino que constituyen meramente razones de primer orden para resolver el caso de que se trate en un determinado sentido. Como razones de primer orden su fuerza respecto de otras razones para resolver el caso en otro sentido -por ejemplo, otros principios- ha de ser ponderada por el propio órgano jurisdiccional ${ }^{15}$.

Del panorama que acabo de trazar no cabe inferir que Atienza y Ruiz Manero postulen que el Derecho guía la conducta de los órganos jurisdiccionales primaria y centralmente mediante reglas de mandato, esto es, mediante razones perentorias y que sólo requiere la deliberación de los órganos jurisdiccionales basada en principios de forma absolutamente excepcional, cuando jueces y tribunales tienen que hacer frente a los casos dificiles. Por el contrario, estos autores se han ocupado de resaltar el hecho de que el Derecho requiere siempre una previa deliberación normativamente guiada. Sólo mediante una deliberación previa, en la que se tienen en cuenta principios, se puede considerar que un caso es subsumible en una determinada regla a adoptar como razón perentoria para la resolución del mismo

\footnotetext{
${ }^{13}$ Cfr. «Commands and Authoritative Legal Reasons», ob. cit., págs. 106 y 107.
}

En realidad esta caracterización no es completa: Las reglas de acción serían razones perentorias e independientes del contenido. El carácter independiente del contenido se refiere al por qué los órganos jurisdiccionales deben obedecer las reglas. Y en este sentido parece que los órganos jurisdiccionales deben considerarlas así por razón de su fuente, es decir, de la autoridad normativa que las ha dictado [Cfr. Las piezas del Derecho... ob. cit., pág. 12].

${ }^{14}$ Cfr. ob. cit., pág. 12.

${ }^{15}$ Cfr. ob. cit., pág. 13 y 21. 
-o, dicho en otros términos, que es un caso fácil-. Esto hace que la dimensión de obediencia a las razones perentorias ya no pueda aparecer como primaria. De cualquier forma, Atienza y Ruiz Manero enfatizan el hecho de que el Derecho no reconoce a cualquier razón válida como integrante legítimo de la deliberación judicial: salvo que el Derecho faculte en algún caso al órgano jurisdiccional para atender a razones distintas de las que él mismo contiene, ha de tratarse de razones contenidas en el propio Derecho ${ }^{16}$.

La puntualización de Atienza y Ruiz Manero en el sentido de que la noción de obediencia a las reglas -en tanto que razones perentorias- no puede ser primaria les ha venido planteando más de una dificultad. En síntesis, creo que las críticas que estos autores han venido recibiendo ${ }^{17}$ pueden resumirse de la siguiente manera: La idea de que las reglas de mandato sean razones perentorias se compadece mal con la existencia de una deliberación previa sobre si adoptarlas o no. Si las reglas son razones perentorias se supone que excluyen toda deliberación sobre la procedencia o no de seguirlas.

Al término de este trabajo voy a intentar mostrar en qué condiciones no resulta incompatible una deliberación previa sobre la procedencia o no de adoptar una regla con la defensa de su carácter de razón perentoria (o protegida) para la acción. Pero antes es necesario que dedique unos minutos al intento de Schauer de explicar el papel de las reglas de mandato en el razonamiento práctico de los órganos primarios.

\section{El positivismo presuntivo de Frederick Schauer}

Antes de comenzar el estudio de la concepción de Schauer ${ }^{18}$ conviene advertir que este autor no diferencia en su análisis entre reglas y principios. No obstante, me parece que, si partimos de una tesis sobre la distinción entre reglas y principios como la que sostienen Atienza y Ruiz Manero, resulta indudable que tanto el análisis estructural como el funcional ${ }^{19}$ de las reglas

\footnotetext{
${ }^{16}$ Cfr. ob. cit., pág. 23.
}

${ }^{17}$ Sobre este particular cfr., entre otros, los trabajos de: Luis Prieto Sanchis, Sobre principios y normas. Problemas del razonamiento jurídico, Centro de Estudios Constitucionales, Madrid, 1992 y «Dúplica a los profesores Manuel Atienza y Juan Ruiz Manero», Doxa. Cuadernos de Filosofía del Derecho, Alicante, núm. 13; Aleksander Peczenik, "Los principios jurídicos según Manuel Atienza y Juan Ruiz Manero», Doxa. Cuadernos de Filosofia del Derecho, Alicante, núm. 12; J. C. Bayón, «Sobre la racionalidad de dictar y seguir reglas», Doxa. Cuadernos de Filosofia del Derecho, Alicante, núm. 19, y de José Juan Moreso, «El encaje de las piezas del Derecho», Analisi e Diritto, Torino, 1997 (en prensa).

\footnotetext{
${ }^{18}$ Voy a tomar como referencia la concepción de las reglas expuesta por Schauer en Playing by the Rules. A Philosophical Examination of Rule-Based Decision-Making in Law and in Life, Oxford Clarendon Press, 1991.
}

\footnotetext{
${ }^{19}$ Aunque voy a construir la exposición diferenciando -como acabo de hacer en la sección anterior- entre aspectos estructurales y funcionales de las reglas de mandato, debo advertir que esta distinción no es expresamente utilizada por Schauer. Ello no obstante. como veremos, los ejes fundamentales de su exposición encuentran acomodo en ella sin mayor dificultad.
} 
desarrollado por Schauer sería aplicable sólo precisamente a las reglas. Esto es, la concepción de Schauer no sería una concepción general de las normas de mandato, sino sólo de aquella subclase de las mismas a las que llamamos reglas.

\section{a) La dimensión estructural de las reglas}

En su análisis estructural de las reglas, Schauer diferencia entre las generalizaciones contenidas en los supuestos de hecho de las reglas y la justificación que subyace a tales reglas. Así, echando mano a un recurrente ejemplo de Schauer, la generalización contenida en la regla que prohíbe la entrada de perros a restaurantes podría ser «ningún perro, en ningún restaurante», mientras que su justificación subyacente podría ser la de evitar molestias a los clientes de restaurantes.

Según Schauer, bajo toda generalización contenida en una prescripción hay una justificación. Mediante la generalización se especifica y simplifica el resultado que normalmente podría obtenerse de la aplicación directa de las justificaciones. Determinar ante cada caso concreto si un determinado agente causas molestias a los clientes de un restaurante es mucho más complejo que determinar si mi ejemplar de foxterrier es o no un perro. En este sentido, Schauer se refiere a las generalizaciones que constituyen reglas como la ejemplificación [instantation] de la justificación subyacente a la regla $\mathrm{a}^{20}$.

Schauer llama experiencias recalcitrantes a todos aquellos supuestos situados en la zona de divergencia extensional entre la ejemplificación y la justificación. Las experiencias recalcitrantes se pueden producir por dos tipos de causa: Por un lado, porque la generalización contenida en el predicado factual de una regla sea supraincluyente, esto es, que comprenda estados de cosas que puedan, en casos particulares, no producir la consecuencia representada en la justificación de la regla -la perrunidad no hace de mi educado ejemplar de foxterrier un perro molesto. Por otro lado, las experiencias recalcitrantes pueden producirse porque el predicado factual sea infraincluyente, es decir, que no comprenda ciertos estados de cosas que pueden contribuir, en casos particulares, a la consecuencia representada en la justificación subyacente a la regla -un niño llorón puede resultar sumamente molesto a los clientes de un restaurante ${ }^{21}$.

Schauer advierte que la posibilidad de una divergencia extensional entre la ejemplificación y la justificación presupone que el significado de la ejemplificación no es coextensivo con su justificación subyacente. Las reglas gozarían de autonomía semántica con respecto a su justificación puesto que el

\footnotetext{
${ }^{20}$ Cfr. ob. cit.. págs. 23 y sig.

${ }^{21}$ Ob. cit., págs. 31 a 34 y 39.
} 
significado de las ejemplificaciones que las componen no se explica completamente por referencia a los propósitos por los que se dictaron las reglas ${ }^{22}$.

b) De la dimensión estructural de las reglas a la funcional. Tipos de sistemas de toma de decisión basados en generalizaciones prescriptivas

Estas características estructurales de las reglas llevan a Schauer a diferenciar, en el plano funcional, cuatro posibles modelos de decisión a partir de reglas: el modelo particularista; el modelo basado en reglas; el particularismo sensible a las reglas; y el positivismo presuntivo. Veamos someramente los rasgos más sobresalientes de cada uno de ellos.

b. 1 El modelo particularista

Para el modelo particularista de toma de decisiones las ejemplificaciones contenidas en las reglas constituyen una guía derrotable para la aplicación de sus justificaciones subyacentes ${ }^{23} \mathrm{y}$, por lo tanto, no ejercen una presión normativa en aquellos casos en los que los resultados a los que éstas apuntan divergen de los resultados apuntados por la aplicación directa de tales justificaciones subyacentes. Mi educado ejemplar de foxterrier tendría, según éste modelo, expedito el paso incluso a los restaurantes más selectos, ya que la «regla» que prohíbe la entrada a perros en los restaurantes es sólo orientativa de que dichos animales pueden ser un elemento molesto para los clientes de restaurantes.

\section{b.2 El modelo basado en reglas}

En cambio, el otro sistema de decisiones, el basado en reglas, atrinchera las ejemplificaciones contenidas en las reglas. Estas ejemplificaciones ejercen presión normativa como tales ejemplificaciones, aún en los casos en los que la aplicación de la ejemplificación frustra la justificación que descansa bajo la $\mathrm{misma}^{24}$. Incluso en el restaurante de la «Asociación de Amigos

${ }^{22}$ Ob. cit., págs. 53 a 55.

Por supuesto, esta visión de las reglas se apoya en una visión más amplia del lenguaje, según la cual éste gozaría de autonomía semántica. Como señala Schauer, los símbolos -palabras, frases, oraciones, etc.tienen la capacidad de transmitir un significado independiente de las intenciones comunicativas con las que los emplea en una ocasión particular el usuario de dichos símbolos. Sobre las críticas y réplicas a esta concepción cfr. ob. cit. págs. 55 a 62.

${ }^{23}$ Cfr. ob cit., pág. 51 .

${ }^{24}$ Conviene advertir que la autonomía semántica de las reglas no es condición suficiente para que el aplicador adopte el modelo basado en reglas. La autonomía semántica es, eso sí, un rasgo necesario para la existencia de un modelo basado en reglas, pero sólo la ausencia de una continua maleabilidad de las reglas es lo que determina la existencia o no del mismo.

Sobre este particular cfr. el libro de RS. Atiyah y R. S Summers, Form and Substance in Anglo-American Law. A Comparative Study of Legal Reasoning, Legal Theory and Legal Institutions, Clarendon Press, Oxford, 1987, págs. 70 y 78 a 79 y el artículo de J.C. Bayón, «Sobre la 
de los Canes» estaría vedado, según este modelo, el acceso a los perros, y de nada serviría argumentar que mantener la prohibición produce más molestias que ventajas a los miembros de la asociación.

El paralelismo entre los dos sistemas de decisión que acabamos de examinar y los criticados por Regan y Raz se revela con singular claridad. El sistema particularista de toma de decisiones implica considerar las reglas como absolutamente transparentes o, lo que es lo mismo, actuar sobre la base del balance de razones de primer orden. En cambio, el sistema basado en reglas supone tratar a las reglas como completamente opacas, lo que equivale a considerar que las reglas resuelven siempre automáticamente todos los problemas prácticos.

En todo caso, es dudoso que ningún sistema jurídico pueda operar consistentemente sólo desde uno de estos dos modelos polares. Como señalan Atiyah y Summers, la posición autoritativa extrema lleva inevitablemente a una aplicación mecánica de las reglas y a la inconsistencia y anomalía del sistema. Pero el sustantivismo extremo tiene también sus problemas. Ningún juez está en disposición de rediseñar todo el universo de razones aplicables a un caso abriendo la decisión a toda la Teoría política y filosófica. El imperio de la ley requiere que existan límites a las razones sustantivas, límites que toman la forma de reglas explícitas y no de meras razones sustantivas que tenderían a ser vagas y menos precisas $^{25}$.

Parece por lo tanto oportuno que dediquemos nuestra atención al estudio de los otros dos modelos de toma de decisión de los que se ocupa Schauer. Estos modelos combinan en diferente medida rasgos de los dos modelos que acabamos de explorar. Se trata del particularismo sensible a las reglas y del positivismo presuntivo.

\section{b.3 Modelo particularista «sensible» a las reglas}

De acuerdo con el particularismo «sensible» a las reglas, éstas son transparentes respecto de su justificación subyacente, tal y como sucede en el modelo particularista, pero, a diferencia de éste, la propia existencia de la regla, en cuanto tal, también se considera una razón a tener en cuenta cuando los resultados indicados por la regla divergen de los indicados por la aplicación directa de su justificación subyacente. Por lo tanto, este modelo tiene en cuenta, por un lado, la justificación sustantiva establecida por las metas o justificaciones subyacentes a las reglas y, por otro lado, la justificación

racionalidad de dictar y seguir reglas», Doxa. Cuadernos de Filosofía del Derecho, Alicante, núm. 19, pág. 155.

${ }^{25}$ Form and Substance in Anglo-American Law... ob. Cit., págs. 70 a 71. 
generada por las propias reglas o, lo que es lo mismo, las ventajas de tener los casos resueltos mediante reglas ${ }^{25}$.

Consecuentemente, quien toma decisiones sobre la base de todo este conjunto de justificaciones -las sustantivas y las generadas por las propias reglas- puede, en algunos casos, llegar a la conclusión de que debe aplicar las reglas incluso aunque éstas apunten a un resultado diferente al señalado por las justificaciones sustantivas tomadas aisladamente. Por supuesto esta conclusión no puede producirse en todos los supuestos, pues en tal caso el conjunto de soluciones al que llevaría aplicar el modelo particularista sensible a las reglas vendría a coincidir con el conjunto de soluciones que arrojaría el modelo basado en reglas, es decir, estaríamos ante dos modelos extensionalmente idénticos. En ocasiones, por lo tanto, quien toma decisiones determinará que las justificaciones sustantivas derrotan las justificaciones generadas por la propia regla, cuando las dos señalen direcciones opuestas ${ }^{26}$.

\section{b.4 Modelo del positivismo presuntivo}

En todo caso, no es el particularismo sensible a las reglas el modelo propugnado por Schauer. Schauer señala que el modelo del positivismo presuntivo es el más adecuado para dar cuenta de los sistemas jurídicos contemporáneos. El positivismo presuntivo es una variedad del modelo basado en reglas que sitúa las ventajas de tener reglas en el momento de su creación y no está abierto a reevaluaciones constantes en el momento de la aplicación de las reglas. Si en lugar de considerar las reglas como instrumentos para lograr la certeza o predecibilidad -como sucedía en el modelo anterior- consideramos las reglas como mecanismos para la distribución del poder, entonces resulta bastante dudoso que sea necesariamente deseable conceder poder al aplicador de normas para determinar si hay que seguir o no las reglas sobre la base del balance de razones aplicables al caso. La idea de Schauer es que este modelo tiene su cabida en sociedades relativamente complejas en las que las reglas tienen un papel importante que jugar de cara a la distribución de competencias. En este tipo de sociedades, el procedimiento de toma de decisiones basado en reglas contribuye a fijar los límites de las competencias de una forma en que no es capaz ningún otro procedimiento de toma de decisiones ${ }^{27}$.

\footnotetext{
${ }^{25}$ Comúnmente se considera que las reglas sirven a valores como la certeza, seguridad o predecibilidad. Schauer señala que las reglas suelen contribuir a tales valores gracias a sus propiedades simplificadoras y a que establecen una designación categorial pública que hace que disminuya la probabilidad de categorizaciones divergentes por parte del destinatario y del aplicador, cuando ambos contemplan la misma regla. Por ejemplo, la justificación para tener una regla que establezca un límite máximo de velocidad en carretera puede ser evitar la incertidumbre de aquéllos a los se va a aplicar la regla [Ob. cit., págs. 94 a 97 y 139].

${ }^{26}$ Ob. cit., págs. 94 a 95 y 97.

${ }^{27}$ Ob. cit., págs. 97 a 98.
} 
Hasta aquí este cuarto modelo podría ser compatible con el modelo basado en reglas. Ahora bien, Schauer apunta a la diferencia extensional entre el modelo basado en reglas y el positivismo presuntivo cuando señala que para el positivismo presuntivo las reglas no precisan ser razones absolutas. Guiarse por una regla no supone necesariamente actuar, consideradas todas las cosas, de acuerdo con la regla. Es posible apartarse puntualmente de lo establecido por las reglas cuando, de no hacerlo así, se produciría un error de una magnitud particularmente grave. En todo caso, más que hablar de una continua revisabilidad de las reglas, para Schauer habría que hablar de un poder para crear excepciones.

Lamentablemente Schauer no es nada explícito con respecto a qué debe entenderse por un error de una magnitud particularmente grave. Como veremos, esta falta de concreción constituye uno de los puntos más débiles de su concepción. La clave para comprender la diferencia extensional entre el particularismo sensible a las reglas y el positivismo presuntivo pasa precisamente por precisar qué es y cuándo se produce un error de una magnitud particularmente grave ${ }^{28}$. Más adelante volveré sobre esta cuestión.

\section{c) Las diferencias con el modelo raziano}

El positivismo presuntivo diferiría, segun Schauer, de la concepción del Derecho como sistema excluyente de Raz. Sintéticamente, podríamos resumir dicha discrepancia de la siguiente forma: Schauer sitúa al juez raziano que quiere evitar experiencias recalcitrantes en la tesitura de tener que recurrir al balance de razones de primer orden para determinar si un supuesto queda fuera del alcance de una regla. Para ilustrar esta idea reformularé el clásico ejemplo que sirvió para iluminar la polémica Hart-Fuller sobre el papel de la intención en la interpretación ${ }^{29}$. Imaginemos un parque público a cuya entrada hay una señal gráfica que prohíbe la entrada de vehículos. Imaginemos también que, como conmemoración de una batalla, un grupo de veteranos de guerra pretende empujar dentro del parque un viejo todoterreno

\footnotetext{
${ }^{28}$ Creo que esta falta de precisión de Schauer está en el origen de la observación de J. C. Bayón en el sentido de que no se percibe una diferencia extensional clara entre el positivismo presuntivo y el particularismo sensible a las reglas [«Sobre la racionalidad de dictar y seguir reglas», ob. cit., pág. 154]. Si de antemano no somos capaces de establecer en qué supuestos se puede hablar de un error grave, y tenemos que estar a expensas de lo que en cada caso concreto resulte del balance de razones aplicables, ciertamente el positivismo presuntivo sería tan sensible al contexto como el particularismo sensible a las reglas. Más adelante sugeriré alguna vía mediante la que Schauer podría dotar de más precisión a su concepción y salir al paso de la crítica que le dirige Bayón.

${ }^{29}$ Cfr. H. L. A. Hart, «Positivism and the Separation of Law and Morals», Harvard Law Review, núm. 71, 1958, págs. 593 a 628 y Lon Fuller «Positivism and Fidelity to Law: A Reply to Professor Hart», ob. cit., págs. 630 a 663.
} 
para exponerlo ${ }^{30}$. Pues bien, según Schauer, el juez raziano no tiene más alternativa que aplicar la regla que prohíbe la entrada de vehículos, o bien declarar que, a la luz de todas las razones de primer orden relevantes para el caso, éste está fuera del alcance de la regla. Schauer considera esta última alternativa poco seductora, ya que implica que son las razones de primer orden las que controlan el caso y que, por lo tanto, no son excluidas.

En cambio, Schauer señala que en su concepción es posible conciliar estos aspectos, partiendo de la diferencia que existe entre realizar un examen cuidadoso de las razones de primer orden y el mero vistazo superficial de las mismas. No sería incompatible con la idea de razón excluyente que un sujeto examinara, tan rápido como fuera posible, las razones de primer orden excluidas para ver si está en presencia de un caso en el que la exclusión de determinados factores debe rechazarse. Este procedimiento de toma de decisiones sería diferente de aquel en el que se espera del agente que examine con idéntico cuidado todas las razones de primer orden ${ }^{31}$.

Nuevamente aparecen aquí expresiones -un vistazo meramente superficial, tan rápido como sea posible- que resultan de contornos particularmente borrosos. En breve me ocuparé de los problemas que suscita el empleo por Schauer de una terminología tan imprecisa para apuntalar distinciones claves en su concepción.

\section{Algunas reflexiones personales}

Hasta aquí hemos examinado cuatro concepciones diferentes -aunque indudablemente relacionadas entre sí- sobre el papel de las reglas de mandato en el razonamiento práctico: La concepción de las reglas indicativas de Donald Regan; la concepción del Derecho como sistema excluyente de Joseph Raz; la concepción de las reglas y los principios de Manuel Atienza y Juan Ruiz Manero; y el positivismo presuntivo de Frederick Schauer. Empleando la terminología de Regan, he pretendido mostrar que todas estas concepciones sitúan el papel de las reglas de mandato en el razonamiento práctico en un espacio intermedio entre la absoluta transparencia y la completa opacidad. No obstante, de lo que acabamos de ver podría desprenderse que, en ese espacio intermedio, Raz y Schauer han desarrollado dos modelos -el de las razones excluyentes y el del positivismo presuntivo- muy alejados entre sí.

\footnotetext{
${ }^{30}$ En rigor, para que el ejemplo funcione, es también menester considerar que el viejo todoterreno constituye, sin ningún genero de dudas, un supuesto de la clase «vehículo». De no ser así el ejemplo no serviría para ilustrar un caso típico de experiencia recalcitrante, sino más bien un problema de interpretación del término «vehículo».

${ }^{31}$ Playing by the Rules, ob. cit., págs. 89 a 91.
} 
Voy a empezar lo que resta de exposición centrándome en las supuestas diferencias entre el modelo perfilado por Schauer y el modelo de Raz. Pretendo demostrar que el aparente desacuerdo en el que estarían ambas concepciones puede no ser más que eso -un aparente desacuerdo-. Mi intención no es hacer filología raziana, mostrando que la interpretación que Schauer hace de la tesis de Raz es más o menos injusta, sino tratar de poner de manifiesto que en el aparato conceptual desplegado por Raz hay elementos suficientes para dar cuenta de los déficits que le atribuye Schauer. Es más, a partir de estos elementos pretendo completar los aspectos que me parecen menos satisfactorios de la concepción de Schauer y realizar algunas reflexiones generales que nos permitan ahondar algo más en el papel de las reglas de mandato en el razonamiento práctico de los aplicadores del Derecho.

a) De nuevo sobre la dimensión funcional de las reglas, la noción de alcance y la de excepción

Para empezar es menester que recordemos alguna cosa sobre la concepción de las reglas de Raz y sobre las nociones de alcance y de excepción. Como ya sabemos, Raz considera que «las reglas son expresiones de compromisos [compromises], o juicios acerca del resultado de conflictos entre razones de primer orden $)^{32}$. Volviendo al ejemplo del parque, supongamos que lo que ha llevado al establecimiento de la señal de prohibición ha sido la intención de que prevalezca la seguridad de los peatones que lo transitan (razón 1), frente a la notable agilización del tráfico que se produciría si se permitiera atravesar el parque para ir de un extremo a otro de la ciudad (razón 2). Aunque para la mayoría de casos la presencia de reglas es decisiva -una señal que prohíbe la entrada de vehículos a un parque no suele suscitar muchas dudas en cuanto a su aplicación-, como hemos visto, Raz advierte que hay factores de complicación que se presentan en una minoría de supuestos. Por lo tanto, las reglas no siempre resuelven automáticamente los problemas prácticos. Puede haber otras razones en conflicto no excluidas

${ }^{32}$ J. Raz, Razón práctica y normas, ob. cit., pág. 232.

Naturalmente, esto no significa que siempre sea fácil, o incluso posible, determinar cuál es el compromiso entre razones que refleja una regla. Para resolver cuestiones de este tipo podemos en ocasiones recurrir a la intención original del legislador, pero no siempre esto es posible o conveniente. A grandes rasgos, cabe decir que la solución a esta cuestión depende de la visión que del Derecho tengan sus aplicadores. Es posible que tengan una visión fuertemente voluntarista, en cuyo caso tiendan a privilegiar el recurso a la intención original del legislador. Pero también cabe que conciban el Derecho como una práctica social compleja, tendente a la resolución de problemas de interacción social. En este caso, los aplicadores tenderán a priorizar los fines socialmente compartidos. 
por las reglas. Por ejemplo, Raz señala que puede haber consideraciones que afecten al alcance de las reglas, o excepciones a las mismas ${ }^{33}$.

Un caso está fuera del alcance de una regla si las principales razones que respaldan la regla no son aplicables a tal caso. En cambio, un caso cae bajo una excepción a la regla cuando le es aplicable algunas de las principales razones en pro de la regla, pero el compromiso (o juicio de prevalencia) expresado en la regla determina que prevalezcan otras consideraciones en conflicto ${ }^{34}$. Aunque la distinción entre la noción de alcance y la de excepción a las reglas puede parecer en ocasiones un tanto borrosa, voy a mantenerla aquí con el fin de no alejarme excesivamente del instrumental analítico de Raz. Si volvemos nuevamente al ejemplo del parque, el supuesto del todoterreno de los veteranos de guerra podría considerarse como un caso fuera del alcance de la regla, ya que el todoterreno no pondría en riesgo la seguridad vial de nadie, ni su introducción en el parque -como es obvio afecta en nada a la fluidez del tráfico en la ciudad. En cambio, si fuera necesario que una ambulancia atravesara el parque para conducir a un accidentado a un hospital, podríamos entender que estamos en presencia de una excepción a la regla, ya que ciertamente la ambulancia puede poner en peligro la seguridad vial, lo que sucede es que el valor de la vida humana prevalece sobre las razones contempladas en el compromiso (o juicio de prevalencia) expresado en la regla ${ }^{35}$. Dicho de otro modo, lo que la regla contempla es simplemente que la seguridad vial (razón 1) prevalece frente a la agilización del tráfico (razón 2), pero no frente a la necesidad de salvar una vida humana (razón 3$)^{36}$.

Una vez que hemos recordado cuál es la concepción de las reglas de Raz, y la noción de alcance y excepción, se entenderá por qué afirmo que un aplicador del Derecho raziano puede resolver ciertas cuestiones relativas al alcance y a las excepciones a las reglas sin reabrir el balance de razones subyacentes. El aplicador del Derecho que autoriza a los veteranos a instalar el todoterreno, o a la ambulancia a pasar por el parque, no tiene por qué volver a realizar un balance con todas las razones de primer orden aplicables al caso. Puede considerar que el compromiso que refleja la regla que prohíbe la entrada de vehículos -la seguridad vial debe prevalecer frente a la agilización del tráfico- es plenamente válido ${ }^{37}$, no obstante lo cual, los

\footnotetext{
${ }^{33}$ Ob. cit., págs. 89 y 91.

${ }^{34}$ Ob. cit., pág. 232.

${ }^{35}$ Por supuesto, del mero compromiso expresado en la regla no se infiere la prevalencia de la vida humana, para llegar a esta conclusión habría que tener en cuenta otras premisas adicionales extraídas del Derecho. Más adelante me ocuparé de esta cuestión.

${ }^{36}$ En este caso diríamos que se aplica una razón incompatible con la regla, pero no excluida por ella. Cfr. ob. cit., pág. 87 .

${ }^{37}$ Con independencia de que él esté de acuerdo o no con dicho compromiso.
} 
dos supuestos -el todoterreno y las urgencias médicas- quedan fuera del alcance de la regla o constituyen una excepción a la misma.

Creo que, antes de proseguir, es menester detenerse un momento para aclarar cierta ambigüedad del término regla que puede estar viciando las diferencias entre Raz y Schauer. Entre otras cosas, por regla se puede entender, bien el significado de una formulación normativa, o bien la expresión de un compromiso (o juicio de prevalencia) entre razones de primer orden. La primera opción es más acorde con la concepción de Schauer, mientras que la segunda es por la que parece decantarse Raz -al menos al referirse a las nociones de alcance y excepción. Pues bien, tiene sentido hablar de atrincheramientos en ambos niveles. Es posible atrincherar tanto significados de formulaciones normativas, como los compromisos (o juicios de prevalencia) entre razones de primer orden que se consideran expresados por las reglas. La primera idea de atrincheramiento es la que tiene Schauer. En cambio, valiéndonos del aparato conceptual de Raz, podríamos entender que el atrincheramiento se puede producir en el nivel del compromiso reflejado en las reglas. $\mathrm{Si}$ éste fuera el caso sería posible, insisto nuevamente, preguntarse por el alcance y las excepciones a una regla sin cuestionar el compromiso entre razones que subyace a la misma. Dicho en términos razianos, sería posible tratar a las reglas -en la segunda acepción de regla antes indicada- como razones excluyentes dentro de su alcance.

\section{b) Las imprecisiones del positivismo presuntivo de Schauer}

De lo que llevamos visto se infiere que además del positivismo puro y duro, descrito por Schauer bajo el rótulo de modelo basado en reglas, cabe todavía una forma de positivismo más moderado, en el que lo que se atrinchera no son ya las ejemplificaciones de las justificaciones subyacentes a las reglas, sino los compromisos (o juicios de prevalencia) entre las razones subyacentes a las reglas. Hasta aquí lo único que he pretendido ha sido resolver lo que me parece que constituye un enmarañado enredo verbal. A continuación me propongo aprovechar el instrumental conceptual raziano que he desplegado para tratar de arrojar alguna luz sobre los aspectos que me parecen más oscuros de la concepción de Schauer.

Tengo dudas de que el positivismo presuntivo sea una buena reconstrucción de lo que el Derecho exige a quienes tienen el deber de aplicar normas -al menos si nos movemos dentro de los parámetros de lo que usualmente se entiende por imperio de la ley-. Recordemos que Schauer mantiene que quienes toman decisiones pueden dejar de lado una regla aplicable a un caso cuando crean que, de no hacerlo así, cometerían un error de una magnitud particularmente grave. Además, para no incurrir en el mismo fallo que achaca a Raz, señala que su tesis no requiere que el aplicador del 
Derecho examine cuidadosamente en todos los casos las razones de primer orden pertinentes, sino que basta con el aplicador eche, tan rápido como sea posible, un mero vistazo superficial a las mismas. Como he venido señalando, me parece que Schauer utiliza expresiones de contornos particularmente borrosos para apuntalar distinciones que son claves en su reconstrucción del papel de las reglas de mandato en la deliberación práctica de los órganos jurisdiccionales.

Se impone pues tratar de dar una respuesta precisa a estas dos cuestiones: ¿Cuándo podemos decir que se ha producido un error de magnitud particularmente grave? y ¿en qué puede consistir el rápido vistazo meramente superficial a las razones de primer orden del que habla Schauer? Para resolver estas cuestiones voy a recurrir a la concepción de las reglas de Raz y, fundamentalmente, a las nociones de alcance y excepción.

\section{c) Errores de primer y de segundo grado}

Si entendemos las reglas, como hace Raz, como expresiones de un compromiso entre razones de primer orden con un alcance característico, podemos vislumbrar qué clases de errores son los que pueden alegar los jueces para no tomar decisiones basadas en reglas en principio aplicables. Salvo en los supuestos de los que luego me ocuparé, el error no puede consistir en que el compromiso entre razones expresado en las reglas esté mal construido. El Derecho no faculta al aplicador de nuestro ejemplo a reabrir, cada vez que aplica la regla, la cuestión de si la seguridad vial debe prevalecer o no sobre la agilización del tráfico. Los sistemas jurídicos contienen balances entre razones de primer orden que son autoritativos, es decir, no susceptibles de ser sometidos a una continua revisión por parte de los aplicadores.

Por contra, el error que permite dejar de lado reglas aplicables es el que se produce cuando el resultado al que llevaría aplicar una regla con autonomía semántica -prohibir la entrada de ambulancias o viejos todoterreno al parque- no se compadece bien con el compromiso entre razones de primer orden expresado en la regla -la seguridad vial prevalece sobre la agilización del tráfico-. Esta falta de adecuación se pondría de manifiesto, singularmente, en los casos de excepción a las reglas, en los que falta alguna consideración en el balance de razones de primer orden -la necesidad de salvar una vida humana- y en los casos que quedan fuera del alcance de las reglas -el viejo todoterreno de los veteranos de guerra-. Siguiendo con esta interpretación, cobra también sentido la afirmación de Schauer de que basta con que los aplicadores echen un vistazo meramente superficial a las razones de primer orden aplicables. Comprobar si un supuesto constituye una excepción a la regla o queda fuera de su alcance es, generalmente, mucho más rápido 
y económico que entrar a reconsiderar la corrección o no del compromiso entre razones de primer orden expresado en las reglas.

Ahora bien, como antes he indicado, hay supuestos excepcionales en los que cabe que los jueces dejen de lado una regla aplicable alegando que el compromiso entre razones expresado en la regla está mal construido. Tal cosa sucede cuando, a la luz de otros compromisos o juicios de prevalencia entre razones, que se hallan implícitos o explícitos en otras partes del sistema jurídico y que son aplicables al caso en cuestión, se aprecia un error en el propio compromiso entre razones de primer orden expresado en la regla ${ }^{38}$. A este tipo de errores podemos llamarlos «errores de segundo grado», frente a los errores debidos a limitaciones en el alcance y a excepciones a las reglas que serían «errores de primer grado». Lo característico de los errores de segundo grado es que la regla fracasa como razón perentoria. No se trata, como en los errores de primer grado, de problemas producidos por el carácter supraincluyente del significado de la formulación normativa, que en nada cuestionan el juicio de prevalencia entre razones de primer orden contenido en la regla; lo que se refuta por erróneo es el propio compromiso entre razones que la regla expresa, por lo que se asume que ésta no debe jugar ningún papel en la toma de decisiones futuras.

En suma, si el planteamiento que acabo de esbozar no es erróneo, brindaría a Schauer la posibilidad de establecer las características genéricas de ciertos supuestos en los que se puede hablar de un error de una magnitud particularmente grave. Habría, por un lado, errores de primer grado, debidos a limitaciones en el alcance y a excepciones a las reglas y, por otro lado, errores de segundo grado, que afectarían al compromiso entre razones de primer orden expresado en las reglas.

d) Algo más sobre el papel de las reglas de mandato en el razonamiento práctico de los aplicadores del Derecho

De lo que llevamos dicho es posible inferir alguna consecuencia general sobre el papel que juegan las reglas de mandato en el razonamiento práctico de los aplicadores del Derecho. Para empezar, creo que tiene pleno sentido afirmar que las reglas de mandato funcionan como razones perentorias en relación con el compromiso (o juicio de prevalencia) entre razones de primer orden que expresan -volviendo al ejemplo: la seguridad vial prevalece frente a la agilización del tráfico-. Me parece dudoso, en cambio, que funcionen como tales cuando lo que se considera es exclusivamente el significado

\footnotetext{
${ }^{38}$ Por supuesto, no estoy contemplando dentro de estos supuestos las antinomias de primer grado entre, para las cuales los sistemas jurídicos cuentan con criterios específicos de resolución.
} 
de las formulaciones normativas -está prohibida la entrada de vehículos. Dicho en otros términos, sólo bajo las formas más extremas de ultrapositivismo sería concebible, aún con riesgo para la propia pervivencia del sistema, prescindir absolutamente de los propósitos e intenciones subyacentes a las reglas.

Afirmar que las reglas son razones perentorias en el primero de los sentidos antes mencionado implica que el aplicador del Derecho no puede componer un nuevo balance de razones cada vez que debe resolver un caso. Su falta de acuerdo con el compromiso entre razones expresado en la regla no es una razón para que deje de aplicarla. El Derecho contiene balances de razones que no pueden estar sometidos a una continua revisión por parte de los órganos de aplicación.

No me es posible ocuparme aquí de las razones que podrían justificar seguir las reglas como razones perentorias, ni de si siempre sería razonable ${ }^{39}$. Tan sólo quiero insistir en que, a la hora de fundamentar el carácter perentorio de las reglas de mandato, suele aludirse a consideraciones relativas a la eficacia del razonamiento que lleva a cabo un agente autónomo -en este caso el juez-: razones como el ahorro de tiempo o trabajo, o la reducción de errores a la hora de decidir qué debe hacerse. Pero a estas razones pueden añadirse otras, derivadas de la legitimidad de determinadas formas de distribución del poder político. La conocida tesis de la filosofía política, según la cual, en principio, la determinación de cuestiones sustantivas debe recaer en autoridades democráticas, y no en autoridades no representativas, como las judiciales, ofrece una alternativa prometedora para fundamentar el carácter excluyente de las reglas de mandato. Desde estos postulados de la filosofía política parece incuestionable que los compromisos entre razones expresados en las reglas por el legislador no pueden ser puestos en tela de juicio en cada acto aplicativo de los mismos.

Que las reglas sean razones perentorias no implica que sean razones absolutas. Como ya sabemos hay dos tipos de situaciones ante las cuales los jueces pueden decidir dejar de lado una regla en principio aplicable, a las que me he referido, respectivamente, como «errores de primer» $\mathrm{y}$ «de segundo grado». Los errores de primer grado se deben a experiencias recalcitrantes causadas por la autonomía semántica de los enunciados mediante los que se expresan las reglas. Haciendo una suerte de síntesis entre el aparato conceptual desplegado por Raz y el desplegado por Schauer, podríamos decir que en estos casos el significado de una formulación normativa deviene supraincluyente en relación al compromiso o juicio de prevalencia entre razones

\footnotetext{
${ }^{39}$ De todo ello me he ocupado con detalle en Sobre la justificación de la autoridad, ob. cit.
} 
de primer orden que la regla expresa. La otra situación en la que los jueces podrían dejar de lado una regla aplicable se produce cuando aprecian un error de segundo grado. Estos errores ya no se deben a experiencias recalcitrantes relacionadas con el significado de la formulación normativa, sino que los produce el propio juicio de prevalencia entre razones de primer orden que la regla expresa. En estos casos lo que se cuestiona es el propio carácter de razón protegida para la acción de la regla.

Ahora bien, tanto en la apreciación de errores de primer grado como en la de errores de segundo grado, el Derecho determina positivamente la conducta de los jueces. En el caso de los errores de primer grado el aplicador del Derecho tiene que demostrar que, «a la luz del sistema de principios que dotan de sentido a la institución o sector normativo en cuestión», el caso en discusión constituye una excepción o está excluido del alcance de la regla. Y las cosas no son muy diferentes en lo que atañe a los errores de segundo grado, también en estos casos tiene pleno sentido afirmar que el Derecho determina positivamente la conducta de los jueces ${ }^{40}$. Para empezar, un juez no puede rechazar por erróneo el compromiso entre razones contenido en una norma jurídica aplicable basándose en razones hasta el momento no reconocidas por el ordenamiento jurídico. Por ejemplo, no puede apelar simplemente a la consecución de los intereses de ciertos grupos sociales, a la realización de programas políticos, a la potenciación de nuevos objetivos sociales o a la promoción de nuevos valores no incorporados hasta el momento al orden jurídico ${ }^{41}$. Razones como éstas sólo pueden ser alegadas por el legislador para justificar la aprobación de una regla que incorpore un nuevo compromiso entre razones de primer orden, o la derogación de una regla que contenga un compromiso que se estime inadecuado, pero nunca pueden ser esgrimidas por los órganos de aplicación.

Además, los jueces tampoco pueden componer a su arbitrio un nuevo compromiso entre las razones de primer orden contenidas en las reglas. Los jueces sólo pueden dejar de lado las reglas oponiendo la prevalencia de otros compromisos entre las razones de primer orden aplicables al caso en cuestión que ya figuran, expresa o tácitamente, en el sistema. En suma, tanto en el caso de los errores de primer grado como en el caso de los de segundo grado, para poder dejar de lado una regla en principio aplicable los jueces tiene que aludir a razones que guardan una estrecha relación con las ideas de validez material y de coherencia del Derecho.

\footnotetext{
${ }^{40}$ Tengo muy en cuenta las consideraciones expresadas por J. Aguiló en «Independencia e imparcialidad de los jueces y argumentación jurídica», Isonomía, México, núm. 6, pág. 75.

${ }^{41}$ Salvo. por supuesto, en el caso de que el Derecho les habilite expresamente para ello. Pero resulta claro que en este supuesto, debido precisamente a dicha habilitación. los jueces no dejan de obrar desde el Derecho.
} 
Ya para concluir, quiero arrojar alguna luz sobre una cuestión que he dejado pendiente al hilo de la concepción sobre las reglas y los principios de Atienza y Ruiz Manero. Recordemos que estos autores mantienen simultáneamente que las reglas de mandato son razones perentorias para la acción y que el aplicador del Derecho debe realizar, ante cada caso concreto, una deliberación previa normativamente guiada sobre la conveniencia o no de aplicar las reglas. Como ya mencioné, la asunción conjunta de ambas tesis ha motivado que se les haya dirigido críticas basadas en la incompatibilidad de ambas afirmaciones. Llegado este momento, podemos establecer las condiciones en las que resulta compatible una deliberación previa sobre la procedencia o no de adoptar una regla con la defensa de su carácter de razón protegida para la acción. Si mi análisis anterior no es errado, es perfectamente concebible que un sujeto, antes de aplicar una regla, delibere sobre si el resultado al que llevaría aplicarla se compadece bien con el compromiso entre razones expresado en la misma, sin que por ello deje de considerar dicha regla ${ }^{42}$ como razón perentoria para la acción. Quien antes de aplicar una regla se pregunta por el alcance o las excepciones a la misma -en los términos que aquí he señalado- no pone en tela de juicio el compromiso o juicio de prevalencia entre razones que la regla expresa. De ahí que un agente pueda considerar perentoria una regla y no aplicarla a un supuesto que considera excluido o fuera del alcance de la misma. El sujeto que actúa de esta manera no está cuestionando el carácter de la regla como razón protegida para la acción.

Las cosas son algo distintas en el caso de los errores de segundo grado, en los que el aplicador del Derecho estima que el sistema jurídico contiene otro balance de razones que es opuesto al expresado en la regla y que es aquél el que debe prevalecer. En estos casos la regla, que en principio era una razón perentoria para la acción, resulta derrotada al entrar en conflicto con otra razón también perentoria para la acción que tiene más peso. No hay nada de extraño en ello, pues sabemos por Raz que, cuando dos (o más) razones de segundo orden son incompatibles, pero no se excluyen mutuamente, se produce un tipo característico de conflicto práctico. Para solucionar tales conflictos hay que prescindir de la dimensión excluyente de las razones en competencia y comparar el peso relativo de cada una de ellas, tomadas en su dimensión de razones de primer orden ${ }^{43}$.

\footnotetext{
${ }^{42}$ En el segundo sentido de regla al que antes he hecho alusión.

${ }^{43}$ Cfr. Razón práctica y normas, ob. cit., págs. 53 y 87.
} 


\section{Bibliografía}

AGUILÓ REGLA, JOSEP, «Independencia e imparcialidad de los jueces y argumentación jurídica», Isonomía, México, núm. 6, págs. 71 a 79.

ATIENZA, MANUEL y RUIZ MANERO, JUAN, Las piezas del Derecho, Ariel Derecho, Barcelona, 1996.

ATIYAH, P. S. y SUMMERS, R. S., Form and Substance in Anglo-American Law. A Comparative Study of Legal Reasoning, Legal Theory, and Legal Institutions, Clarendon Press, Oxford, 1987.

BAYÓN MOHNO, J. C., "Sobre la racionalidad de dictar y seguir reglas», Doxa. Cuadernos de Filosofía del Derecho, Alicante, núm. 19, 1997, págs. 143 a 180.

FULLER, LON, «Positivism and Fidelity to Law: A Reply to Professor Hart», Harvard Law Review, núm. 71, 1958, págs. 630 a 663.

HART, H. L. A., «Positivism and the Separation of Law and Morals», Harvard Law Review, núm. 71, 1958, págs. 593 a 628 .

HART, H. L. A., «Commands and Authoritative Legal Reasons», Authority, Joseph Raz ed., Basil Blackwell, Oxford, 1990.

MORESO, JOSÉ JUAN, «El encaje de las piezas del Derecho», Analisi e Diritto, Torino, 1997 (en prensa).

PECZENIK, ALEKSANDER, «Los principios jurídicos según Manuel Atienza y Juan Ruiz Manero», Doxa. Cuadernos de Filosofia del Derecho, Alicante, núm. 12.

PRIETO SANCHIS, LUIS, Sobre principios y normas. Problemas del razonamiento jurídico, Centro de Estudios Constitucionales, Madrid, 1992.

PRIETO SANCHIS, LUIS, «Dúplica a los profesores Manuel Atienza y Juan Ruiz Manero», Doxa. Cuadernos de Filosofía del Derecho, Alicante, núm. 13.

RAZ, JOSEPH, La autoridad del Derecho. Ensayos sobre derecho y moral (trad. de R. Tamayo Salmorán), UNAM, México, 1982.

RAZ, JOSEPH, Razón práctica y normas (trad. de Juan Ruiz Manero), Madrid, Centro de Estudios Constitucionales, 1991.

REGAN, DONALD, «Law's Halo», Philosophy and Law, J. Coleman y E. Frankel Paul eds., Basil Blackwell, Oxford, 1987, págs. 15 a 30.

REGAN, DONALD, «Authority and Value: Reflections on Raz's Morality of Freedom», Southern California Law Review, núm. 62, 1989, págs. 995 a 1095.

RÓDENAS CALATAYUD, ANGELES, Sobre la justificación de la autoridad, Centro de Estudios Constitucionales, Madrid, 1996.

SCHAUER, FREDERICK, Playing by the Rules. A Philosophical Examination of Rule-Based Decision-Making in Law and in Life, Clarendon Press, Oxford, 1991. 
DOXA 21-I (1998) 